\title{
Accelerator-Driven System Analysis by Using Different Nuclear Data Libraries
}

\author{
T. Sugawara ${ }^{{ }^{\star}}$, Ts. Zolbadral ${ }^{2}$, K. Nishihara ${ }^{1}$, K. Tsujimoto ${ }^{1}$ \\ ${ }^{1}$ Japan Atomic Energy Agency, Shirakata-shirane 2-4, Tokai-mura, Naka-gun, Ibaraki 319-1195, Japan \\ ${ }^{2}$ National University of Mongolia, P.O.Box:36-232, Ulaanbaatar, 17032, Mongolia
}

\section{ARTICLE INFO}

Article history:

Received 29 June 2012

Revised in Revised form 22 August 2012

Accepted 30 August 2012

Keywords:

Accelerator-driven system (ADS)

Transmutation

Neutronic design

Nuclear data library

Burn-up calculation

\begin{abstract}
A B S T R A C T
An accelerator-driven system (ADS) has been investigated to transmute minor actinide (MA) included in high-level waste. In the neutronic design of the ADS, the accuracy of nuclear data for MA and lead bismuth (LBE) which is the candidate material for coolant and spallation target, is important. To know the current accuracy of nuclear data libraries, this study aims to compare representative nuclear data libraries, JENDL-4.0, 3.3, ENDF/B-VII.1 and VII.0 through the neutronic calculation of the ADS geometry proposed as the IAEA benchmark problem. The calculation results showed that about $1.1 \% \mathrm{dk}, 0.7 \% \mathrm{dk}$ and $2.7 \% \mathrm{dk}$ differences were observed between JENDL-4.0 and ENDF/B-VII.1, ENDF/B-VII.0 and JENDL-3.3 at the beginning of cycle, respectively. These results mean that the current nuclear data libraries are still insufficient for the neutronic design of the ADS. The enhancement of nuclear data libraries by cross section measurement is required and, moreover, integral experiments with MA and LBE isotopes are essential.
\end{abstract}

(C) 2012 Atom Indonesia. All rights reserved

\section{INTRODUCTION}

The Japan Atomic Energy Agency (JAEA) has investigated an accelerator-driven system (ADS) to transmute minor actinide (MA) included in high-level waste (HLW) discharged from nuclear power plants [1]. The ADS investigated in JAEA is a lead bismuth eutectic (LBE) cooled tank type ADS with $800 \mathrm{MW}$ thermal power. Such reactor, which has large amount of MA and LBE, has never been constructed and operated, so the accuracy of nuclear data for MA and LBE is very important from the viewpoint of neutronic design. To improve and overcome this issue, analytical investigations have been performed $[2,3]$ and experimental ones are required.

In association with the above situation, the JAEA 800MW ADS [4] benchmark problem was proposed as one of the problems discussed in the International Atomic Energy Agency (IAEA) Coordinated Research Project (CRP) on "Analytical and experimental benchmark analyses of accelerator driven systems [5]". The purpose of this benchmark problem was to obtain fundamental knowledge of calculation accuracy for a commercial grade ADS. The results were summarized and it was found that the

\footnotetext{
* Corresponding author.

E-mail address: sugawara.takanori@jaea.go.jp
}

difference of k-effective was 2 to $3 \% \mathrm{dk}$ among the different nuclear data libraries (JENDL-4.0, 3.3, ENDF/B-VII.0, JEFF-3.1, 3.0) [6].

This study aims to compare the k-effective value at beginning of cycle (BoC), end of cycle $(\mathrm{EoC})$ and a burn-up reactivity by using different nuclear data libraries with the same geometry proposed in the IAEA benchmark problem. Recently, the latest version of ENDF/B-VII library, ENDF/B-VII.1 was published [7]. So, the comparison between the results calculated by JENDL-4.0 [8] and ENDF/B-VII.1 is the main purpose of this study. The results calculated by JENDL-3.3 [9] and ENDF/B-VII.0 [10] are also investigated. Additionally, the effect by changing a burn-up chain used for the burn-up calculation was also estimated because a new burnup chain was published from JAEA [11].

\section{CALCULATION METHOD}

\section{Calculation model}

A cylindrical RZ calculation model of the JAEA $800 \mathrm{MW}$ ADS, which was proposed as the IAEA benchmark problem was employed. Figure 1 shows the RZ calculation model and Table 1 presents the initial homogeneous number densities of each region. 


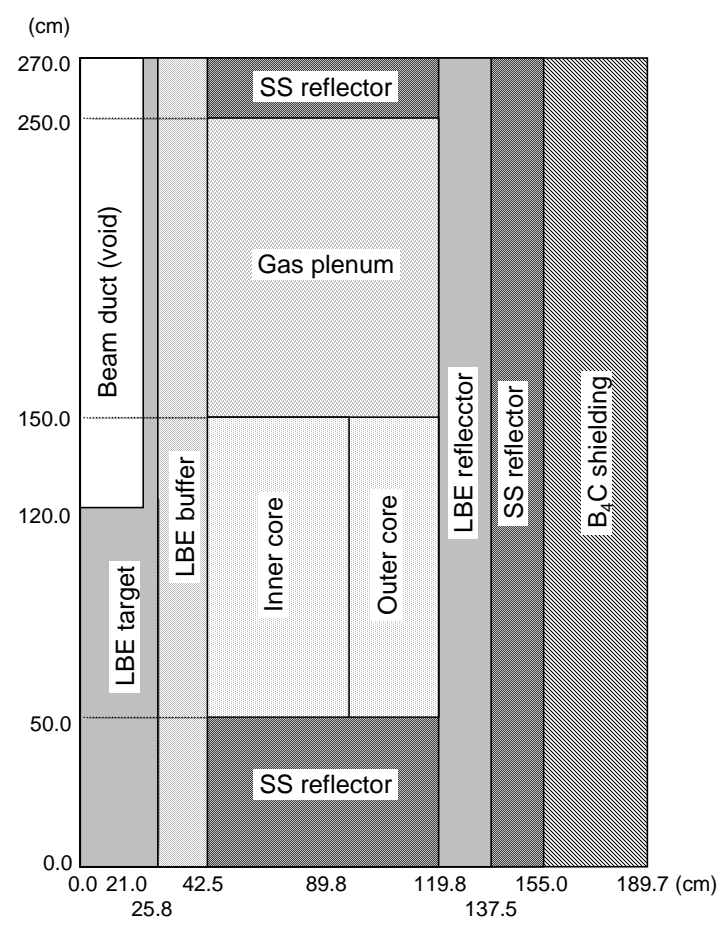

Fig. 1. RZ calculation model of the ADS.

Table 1. Initial homogeneous number densities of each region $\left(\times 10^{24} / \mathrm{cm}^{3}\right)$

\begin{tabular}{ccc}
\hline & Inner fuel & Outer fuel \\
\hline${ }^{15} \mathrm{~N}$ & $8.309 \mathrm{E}-03$ & $8.309 \mathrm{E}-03$ \\
$\mathrm{Cr}$ & $1.785 \mathrm{E}-03$ & $1.785 \mathrm{E}-03$ \\
$\mathrm{Mn}$ & $9.939 \mathrm{E}-05$ & $9.939 \mathrm{E}-05$ \\
$\mathrm{Fe}$ & $6.599 \mathrm{E}-03$ & $6.599 \mathrm{E}-03$ \\
$\mathrm{Ni}$ & $1.116 \mathrm{E}-03$ & $1.116 \mathrm{E}-03$ \\
$\mathrm{Zr}$ & $5.675 \mathrm{E}-03$ & $5.675 \mathrm{E}-03$ \\
$\mathrm{Mo}$ & $1.423 \mathrm{E}-04$ & $1.423 \mathrm{E}-04$ \\
$\mathrm{~Pb}$ & $7.833 \mathrm{E}-03$ & $7.833 \mathrm{E}-03$ \\
${ }^{209} \mathrm{Bi}$ & $9.686 \mathrm{E}-03$ & $9.686 \mathrm{E}-03$ \\
${ }^{234} \mathrm{U}$ & $3.469 \mathrm{E}-07$ & $4.964 \mathrm{E}-07$ \\
${ }^{236} \mathrm{U}$ & $8.600 \mathrm{E}-08$ & $1.230 \mathrm{E}-07$ \\
${ }^{237} \mathrm{~Np}$ & $8.962 \mathrm{E}-04$ & $7.131 \mathrm{E}-04$ \\
${ }^{238} \mathrm{Pu}$ & $2.030 \mathrm{E}-05$ & $2.904 \mathrm{E}-05$ \\
${ }^{239} \mathrm{Pu}$ & $4.625 \mathrm{E}-04$ & $6.618 \mathrm{E}-04$ \\
${ }^{240} \mathrm{Pu}$ & $2.103 \mathrm{E}-04$ & $2.972 \mathrm{E}-04$ \\
${ }^{241} \mathrm{Pu}$ & $9.137 \mathrm{E}-05$ & $1.307 \mathrm{E}-04$ \\
${ }^{242} \mathrm{Pu}$ & $5.837 \mathrm{E}-05$ & $8.351 \mathrm{E}-05$ \\
${ }^{241} \mathrm{Am}$ & $5.790 \mathrm{E}-04$ & $4.665 \mathrm{E}-04$ \\
${ }^{242 m} \mathrm{Am}$ & $1.061 \mathrm{E}-06$ & $8.439 \mathrm{E}-07$ \\
${ }^{243} \mathrm{Am}$ & $2.354 \mathrm{E}-04$ & $1.873 \mathrm{E}-04$ \\
${ }^{243} \mathrm{Cm}$ & $5.281 \mathrm{E}-07$ & $4.202 \mathrm{E}-07$ \\
${ }^{244} \mathrm{Cm}$ & $7.083 \mathrm{E}-05$ & $5.635 \mathrm{E}-05$ \\
${ }^{246} \mathrm{Cm}$ & $6.809 \mathrm{E}-06$ & $5.418 \mathrm{E}-06$ \\
\hline & $6.956 \mathrm{E}-07$ & $5.534 \mathrm{E}-07$ \\
\hline
\end{tabular}

\begin{tabular}{cccccc}
\hline & $\begin{array}{c}\text { LBE } \\
\text { target }\end{array}$ & $\begin{array}{c}\text { Gas } \\
\text { plenum }\end{array}$ & $\begin{array}{c}\text { LBE } \\
\text { reflector }\end{array}$ & $\begin{array}{c}\text { SUS } \\
\text { reflector }^{\text {a) }}\end{array}$ & $\begin{array}{c}\mathrm{B}_{4} \mathrm{C} \\
\text { shielding }\end{array}$ \\
\hline${ }^{10} \mathrm{~B}$ & & & & & $1.180 \mathrm{E}-02$ \\
${ }^{11} \mathrm{~B}$ & & & & & $4.751 \mathrm{E}-02$ \\
$\mathrm{C}$ & & & & & $1.483 \mathrm{E}-02$ \\
$\mathrm{Cr}$ & & $1.785 \mathrm{E}-03$ & $1.069 \mathrm{E}-02$ & $3.055 \mathrm{E}-03$ & $3.055 \mathrm{E}-03$ \\
$\mathrm{Mn}$ & $9.939 \mathrm{E}-05$ & $5.952 \mathrm{E}-04$ & $1.701 \mathrm{E}-04$ & $1.701 \mathrm{E}-04$ \\
$\mathrm{Fe}$ & & $6.599 \mathrm{E}-03$ & $3.952 \mathrm{E}-02$ & $1.129 \mathrm{E}-02$ & $1.129 \mathrm{E}-02$ \\
$\mathrm{Ni}$ & $1.116 \mathrm{E}-03$ & $6.686 \mathrm{E}-03$ & $1.910 \mathrm{E}-03$ & $1.910 \mathrm{E}-03$ \\
$\mathrm{Mo}$ & $1.423 \mathrm{E}-04$ & $8.521 \mathrm{E}-04$ & $2.434 \mathrm{E}-04$ & $2.434 \mathrm{E}-04$ \\
$\mathrm{~Pb}$ & $1.321 \mathrm{E}-02$ & $7.833 \mathrm{E}-03$ & $3.990 \mathrm{E}-03$ & $1.064 \mathrm{E}-02$ & $2.660 \mathrm{E}-03$ \\
${ }^{209} \mathrm{Bi}$ & $1.634 \mathrm{E}-02$ & $9.686 \mathrm{E}-03$ & $4.934 \mathrm{E}-03$ & $1.316 \mathrm{E}-02$ & $3.289 \mathrm{E}-03$ \\
\hline a) LBE buffer region is the same as SUS reflector & &
\end{tabular}

The ADS consists of a proton accelerator, a spallation target and a sub-critical core. The proton beam is injected from the beam duct shown in Fig. 1 and spallation neutrons are generated in the spallation target (LBE target in Fig. 1). The subcritical core is driven by the spallation neutrons, and MAs which are loaded in the inner and outer cores shown in Fig. 1, are transmuted by the spallation neutrons or fission neutrons generated by MAs.

The thermal power is $800 \mathrm{MW}$ and a burn-up period is 600 effective full power days (EFPDs). For the fuel, a nitride fuel of MA and plutonium is employed and zirconium-nitride $(\mathrm{ZrN})$ is used as the inert matrix of the fuel. To avoid the production of $\mathrm{C}-14$ whose half-life is very long $(5730 \mathrm{y})$, nitrogen$15(\mathrm{~N}-15)$ is used for both (MA, Pu)-nitride and $\mathrm{ZrN}$. The isotopic composition of MA and $\mathrm{Pu}$ are based on the following assumptions: the PWR spent fuel with $45 \mathrm{GWd} / \mathrm{t}$ burn-up cooled for 7 years before reprocessing and MA and $\mathrm{Pu}$ are cooled for 3 years before fabricated to the ADS fuel. Other details are based on Ref. [4].

\section{Calculation code}

The MVP/MVP-BURN codes are employed for the calculation. The MVP code is a general purpose Monte Carlo code for neutron and photon transport calculations based on continuous energy [12]. The MVP-BURN code [13] enables the burnup calculations using a continuous-energy Monte Carlo code MVP. In this study, the burn-up calculation with the eigen-mode was performed. Although this calculation mode ignores the external neutron source such as the spallation neutron, it has no problem to compare the nuclear data libraries and it can shorten the computational time.

For the nuclear data library, JENDL-4.0, JENDL-3.3, ENDF/B-VII.1 and ENDF/B-VII.0 are used as described above. The calculation case with JENDL-4.0 is the reference case in this study. For ENDF/B-VII.1, the beta version of the nuclear data 
library for the MVP code [14] was used because the library is under development and this study is a part of verification for it.

\section{Calculation case}

Three comparisons were carried out by using different nuclear data libraries or burn-up chain.

(1) First of all, a verification of the new burn-up chain, ChainJ40 [11] was performed. In this comparison, JENDL-4.0 was used for all nuclides and burn-up calculation results with ChainJ40 and ChainOLD [13], which had been used until the release of ChainJ40 were investigated. The main differences of these burn-up chains are the number of nuclide in the chain and the update of fission yield data. In the following cases, ChainJ40 was employed as the burn-up chain.

(2) Nuclear data library of all nuclides was changed from JENDL-4.0 to others and the burn-up calculations were performed. The change of k-effective (k-swing) was compared.

(3) To know the contribution of each nuclide to differences which would be shown in case (2), burn-up calculations with changing the nuclear data library from JENDL-4.0 to JENDL-3.3 or ENDF/B-VII.1 or ENDF/B-VII.0 for each nuclide were performed.

\section{RESULTS AND DISCUSSION}

\section{Comparison for burn-up chain}

The calculation results with the use of different burn-up chains were presented in Table 2. $k_{B o C}$ and $k_{E O C}$ mean the k-effective values at $\mathrm{BoC}$ and EoC, and the burn-up reactivity $\rho$ burn $[\mathrm{dk} / \mathrm{kk}$ '] was calculated by the following equation;

$$
\rho_{\text {burn }}=\frac{k_{B o C}-k_{E O C}}{k_{B o C} k_{E o C}}
$$

In the BoC, the k-effective values were almost same but the k-effective difference, which was larger than the statistical error, was observed in the EoC. For the burn-up reactivity, $5.3 \times 10^{-4} \mathrm{dk} / \mathrm{kk}^{\prime}$ difference was presented and the burn-up reactivity with the use of ChainJ40 was larger than the ChainOLD case although the difference is approximately-same as the statistical error.
Table 2. Calculation results with the use of different burn-up chain.

\begin{tabular}{ccc}
\hline & ChainJ40 & ChainOLD \\
\hline$k_{B o C}$ & $0.97760 \pm 0.00034$ & $0.97784 \pm 0.00033$ \\
$k_{E o C}$ & $0.93504 \pm 0.00034$ & $0.93573 \pm 0.00032$ \\
$\rho_{\text {burn }}$ & $4.656 \times 10^{-2} \pm 5.3 \times 10^{-4}$ & $4.603 \times 10^{-2} \pm 5.0 \times 10^{-4}$ \\
\hline
\end{tabular}

To investigate the cause of the burn-up difference, changes of atomic number density $d N_{\text {chain }}$

$$
d N_{\text {chain }}=N_{E O C}^{\text {chain }}-N_{B O C}^{\text {chain }}
$$

for each nuclide was calculated; here, $N$ is the atomic number density at $\mathrm{BoC}$ or $\mathrm{EoC}$ for each nuclide and chain is ChainJ40 or ChainOLD. The changes, $d N_{\text {ChainJ40 }}$ and $d N_{\text {ChainOLD }}$ for the inner and outer core are shown in Fig. 2 and 3, respectively.

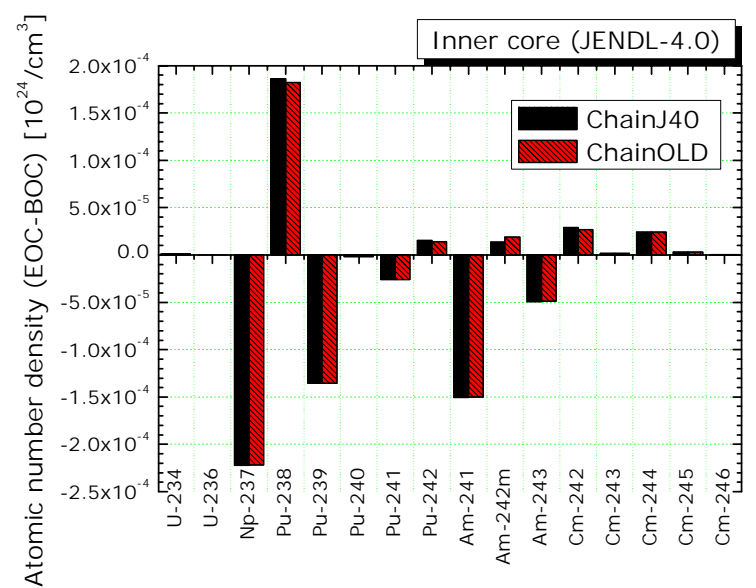

Fig. 2. Difference of atomic number density between EoC and BoC (Inner core).

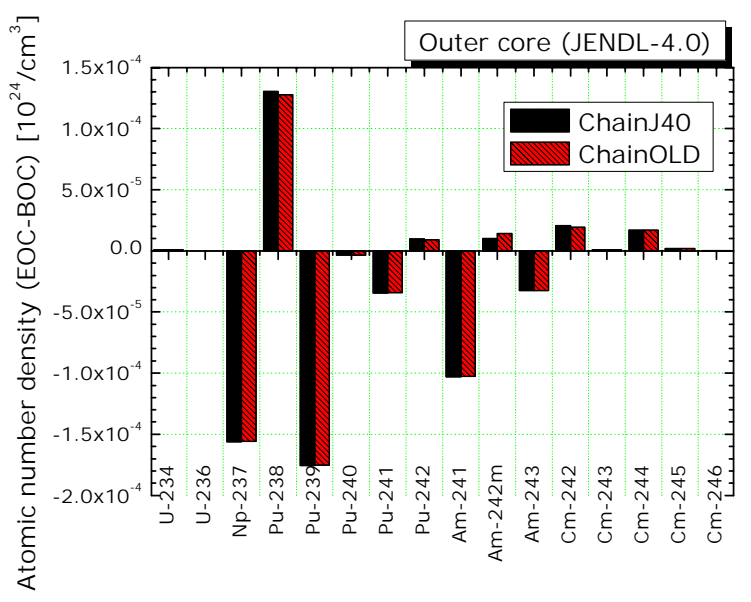

Fig. 3. Difference of atomic number density between EoC and BoC (Outer core). 
The differences were observed for $\mathrm{Pu}-238$, $\mathrm{Pu}-242$, Am-242m and $\mathrm{Cm}-242$ by changing the burn-up chain. To compare these differences quantitatively, the following amount $D_{l}$ was calculated for each nuclide,

$$
D_{1}=\frac{d N_{\text {ChainOLD }}-d N_{\text {Chain } 40}}{d N_{\text {ChainJ } 40}}
$$

and illustrated in Fig. 4. In this figure, some nuclides whose values of $d N_{\text {chain }}$ were very small, were abbreviated.

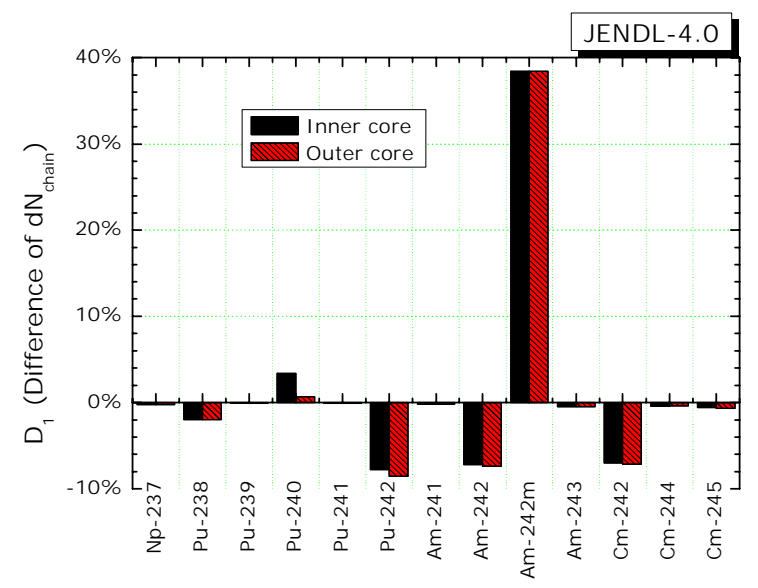

Fig. 4. Comparison of $D_{l}$ value for each nuclide.

From these results, it was found the difference of Am-242m was dominant in this comparison. The $D_{l}$ value of Am-242m was $38 \%$ and it means a generation amount of Am-242m calculated by ChainOLD was $38 \%$ larger than that calculated by ChainJ40. One of the main revised points from ChainOLD to ChainJ40 is the change of isomer-state branching ratio of Am-241 capture reaction (IR in the following). The $I R$ is defined as the following equation;

$$
I R=\frac{N_{\mathrm{Am}-242 \mathrm{~g}}}{N_{\mathrm{Am}-242 \mathrm{~g}}+N_{\mathrm{Am}-242 \mathrm{~m}}}
$$

Here, $N_{\text {Am-242g }}$ and $N_{\mathrm{Am}-242 \mathrm{~m}}$ are the atomic number densities of grand state and metastable Am242 after the neutron capture reaction of Am-241.

The $I R$ in ChainOLD is 0.7936 and that in ChainJ40 is 0.8499. It means the amount of Am-242 calculated by ChainOLD is about $7.1 \%$ smaller than the one calculated by ChainJ40. Figure 4 indicates the almost same result.

From the $I R$ value, the ratios of $A m-242 \mathrm{~m}$ generation are calculated as 0.2064 in ChainOLD and 0.1501 in ChainJ40. It means the amount of Am-242m calculated by ChainOLD is $37.5 \%$ larger than the one calculated by ChainJ40, and the results shown in Fig. 4 presents the same tendency. Based on the difference of the $I R$, the amounts of other daughter nuclides of Am-242g such as $\mathrm{Pu}-238, \mathrm{Pu}-242$ and $\mathrm{Cm}-242$ are also different between ChainOLD and ChainJ40.

In the previous investigation [15], the sensitivity analysis of the burn-up reactivity for the same ADS geometry was performed. The sensitivity coefficient of Am- $242 \mathrm{~m}$ against the burn-up reactivity was the negative value. It means the burn-up reactivity decreases if the amount of Am-242m increases. In this calculation, the generation amount of Am-242m calculated by ChainOLD was larger than that calculated by ChainJ40. This is why the burn-up reactivity calculated by ChainOLD is smaller than the one calculated by ChainJ40 as shown in Table 2 .

\section{Comparison for k-swing}

Figure 5 shows the changes of k-effective with the use of each nuclear data library. Table 3 summarizes the burn-up reactivity for each case.

At the $\mathrm{BoC}$, about $1.1 \% \mathrm{dk}$ difference was observed between JENDL-4.0 and ENDF/B-VII.1. About $0.7 \% \mathrm{dk} / 2.7 \% \mathrm{dk}$ differences were obtained between JENDL-4.0 and ENDF/B-VII.0 / JENDL3.3. These results mean that the current nuclear data libraries are still insufficient for the neutronic design of the ADS because the target accuracy of $\mathrm{k}$-effective at the $\mathrm{BoC}$ is $0.3 \% \mathrm{dk}[2,16]$.

For the burn-up reactivity, the differences against the JENDL-4.0 result were $-0.065 \% \mathrm{dk} / \mathrm{kk}$, $-0.706 \% \mathrm{dk} / \mathrm{kk}$ ' and $0.619 \% \mathrm{dk} / \mathrm{kk}$ ' in JENDL-3.3, ENDF/B-VII.1 and ENDF/B-VII.0 results, respectively. The difference of the burn-up reactivity between JENDL libraries was small although that of k-effective at the $\mathrm{BoC}$ was large. For the ENDF/B-VII libraries, the tendency of the burn-up was different as shown in Fig .5 and the difference of the burn-up reactivity was very large.

To investigate the cause of these differences for the burn-up reactivity, the difference of the atomic number density for each nuclide at the EoC, $D_{2}$, was calculated as

$$
D_{2}=N_{E O C}^{L i b}-N_{E O C}^{J 40}
$$

where $N_{E O C}^{L i b}$ is the atomic number density at the EoC by using a nuclear data library 'Lib' (JENDL3.3, ENDF/B-VII.1 or VII.0) and $N_{E O C}^{J 40}$ is that by using the JENDL-4.0 library. Figure 6 presents the difference $D_{2}$ of the dominant nuclides in the inner core. 
In terms of JENDL-3.3, the $D_{2}$ values of $\mathrm{Pu}-238, \mathrm{Am}-241$ and curium isotopes were large. However, for the dominant nuclides such as Np-237 and $\mathrm{Pu}-239$, the $D_{2}$ values were very small. This is why the difference of the burn-up reactivity was not so large between JENDL-4.0 and JENDL-3.3. It was supposed that other nuclides except $\mathrm{MA}$ and $\mathrm{Pu}$ would be the cause of the large k-effective difference at the BoC.

On the other hand, in terms of ENDF/B-VII.1 and VII.0, there were differences in Np-237 and $\mathrm{Pu}$ 239. This is one of the causes of the difference for the burn-up reactivity against the JENDL-4.0 result. For other isotopes such as Am-243, Cm-244, Cm245, the $D_{2}$ values of ENDF/B-VII.1 and VII.0 were different. It was supposed that a significant revision was performed from ENDF/B-VII.0 to VII.1 for these isotopes.

Table 3. Burn-up reactivity with the use of each nuclear data library

\begin{tabular}{cc}
\hline & $\rho_{\text {burn }}[\mathrm{dk} / \mathrm{kk}]$ \\
\hline JENDL-4.0 & $4.656 \times 10^{-2} \pm 5.3 \times 10^{-4}$ \\
JENDL-3.3 & $4.591 \times 10^{-2} \pm 5.4 \times 10^{-4}$ \\
ENDF/B-VII.1 & $3.950 \times 10^{-2} \pm 5.2 \times 10^{-4}$ \\
ENDF/B-VII.0 & $5.275 \times 10^{-2} \pm 5.6 \times 10^{-4}$ \\
\hline
\end{tabular}

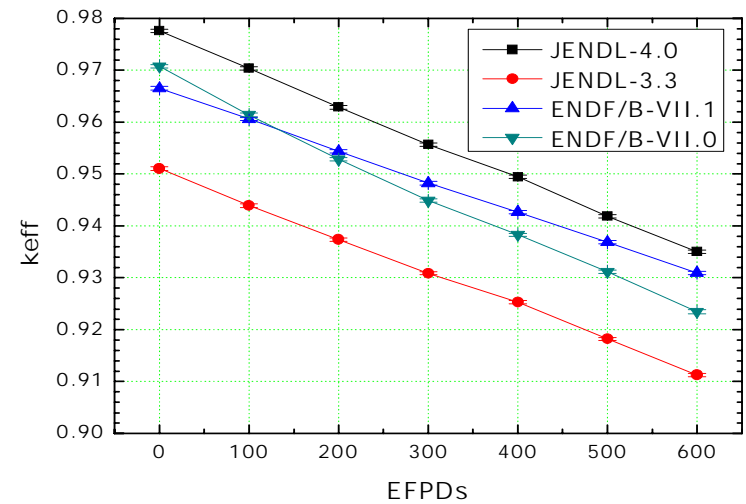

Fig. 5. Change of k-effective with the use of each nuclear data library

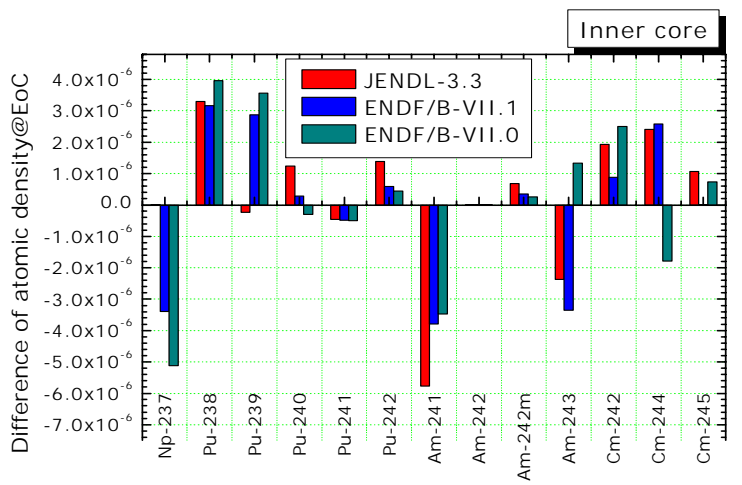

Fig. 6. Difference of atomic number density at EoC, $D_{2}$ (Inner core).

\section{Effect by using other nuclear data library}

To know the contribution of each nuclide to differences shown in Fig. 5, moreover, the burn-up calculations with changing the nuclear data library from JENDL-4.0 to JENDL-3.3, ENDF/B-VII.1 and ENDF/B-VII.0 for each nuclide were carried out. Figure 7 shows the calculation result for k-eff at BoC and EoC of the JENDL-3.3 case for dominant nuclides. In this figure, 'Np-237' means the result by using the input data whose nuclear data library was JENDL-4.0 except Np-237. Then, as the nuclear data library of Np-237, JENDL-3.3 was used. The result 'All' in Fig. 7 corresponds to the result shown in Fig. 5. The same calculations were performed with the use of ENDF/B-VII.1 and VII.0 and these results were summarized in Fig. 8 and 9, respectively.

Figure 7 presents that $\mathrm{Am}-241, \mathrm{Pu}-239$, $\mathrm{Pb}-206$ and $\mathrm{Pb}-207$ were the main causes in the JENDL-3.3 case. At the EoC, the same tendency was observed.

For the ENDF/B-VII.1 case, Np-237, Am-241, $\mathrm{Pu}-239$ and $\mathrm{N}-15$ were the main contributions. At the EoC, on the other hand, the differences in $\mathrm{Np}-237$ and $\mathrm{Pu}-239$ became small. It is difficult to explain the reason why the difference at the EoC decreases because the changes of the atomic number density, the neutron flux and the nuclear data are the main factors in the burn-up calculation. It was expected that the change of the atomic number density and the neutron flux canceled the effect by changing the nuclear data library.

Figure 9 indicates that Np-237. Am-241, $\mathrm{Pu}-239$ and $\mathrm{N}-15$ were the main causes in the ENDF/B-VII.0 case. This tendency was similar to the ENDF/B-VII.1 case.

For the burn-up reactivity, a systematic result was not indicated as shown in Fig. 10 because the changes of the number density, the neutron flux and the nuclear data affect the burn-up calculation as described above. However, for Am-241 and Pu-239, it was expected that the effects by changing the nuclear data library were observed because the effects of these nuclides were larger than that of others. For example, Fig. 11 compares the cross section data for the neutron capture reaction of Am241 in JENDL-4.0 and ENDF/B-VII.1. This figure also presents the sensitivity coefficient of Am-241 neutron capture reaction for the burn-up reactivity [15]. Since the sensitivity coefficient is the negative value from $1 \mathrm{keV}$ to $1 \mathrm{MeV}$ energy region, the burnup reactivity would decrease if the cross section for neutron capture reaction increases. In this energy region, the cross section in ENDF/B-VII. 1 is several percent larger than that in JENDL-4.0. This is the 
cause for the difference of the burn-up reactivity in the Am-241 case shown in Fig. 10.

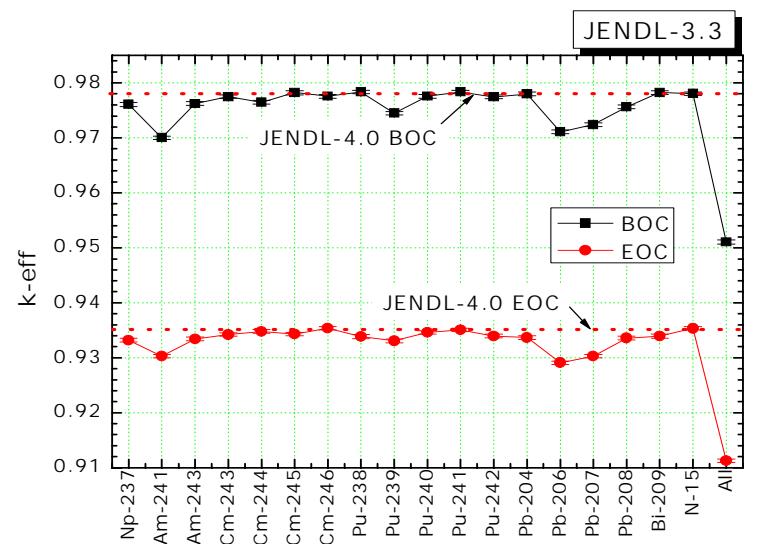

Fig. 7. Effective multiplication factor (k-eff) by changing the nuclear data library from JENDL-4.0 to JENDL-3.3. 'Np-237' means the result by using the input data whose nuclear data library was JENDL-4.0 except Np-237. Then, as the nuclear data library of Np-237, JENDL-3.3 was employed. 'All' corresponds to the result shown in Fig. 5.

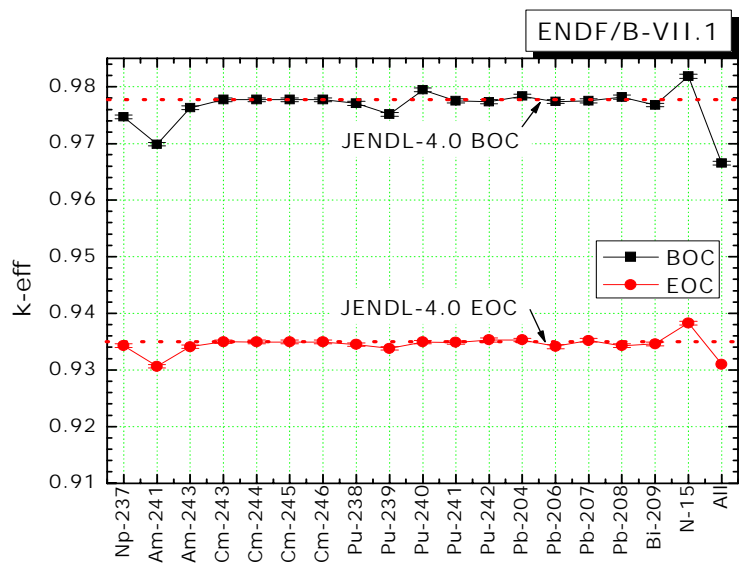

Fig. 8. Effective multiplication factor by changing the nuclear data library from JENDL-4.0 to ENDF/B-VII.1.

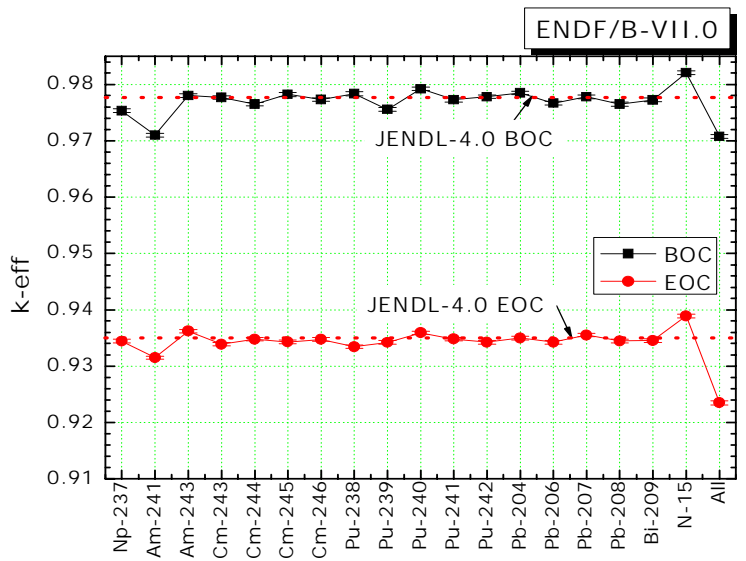

Fig. 9. Effective multiplication factor by changing the nuclear data library from JENDL-4.0 to ENDF/B-VII.0.

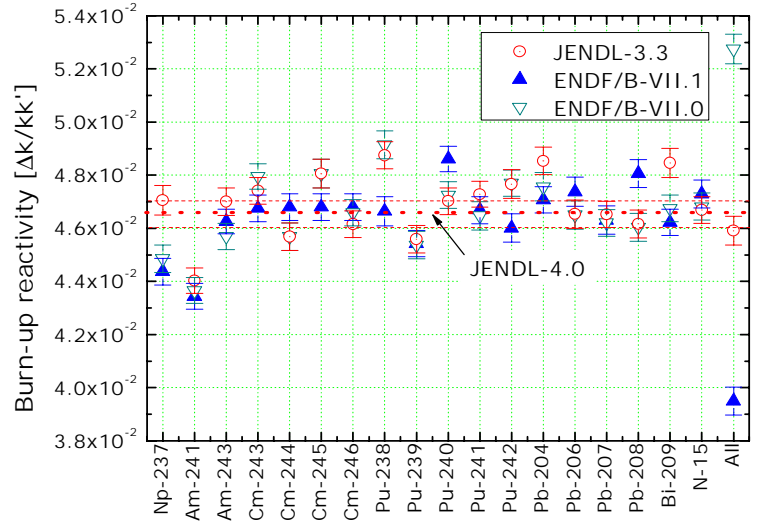

Fig. 10. Burn-up reactivity by changing the nuclear data library from JENDL-4.0 to JENDL-3.3, ENDF/B-VII.1 and ENDF/BVII.0.

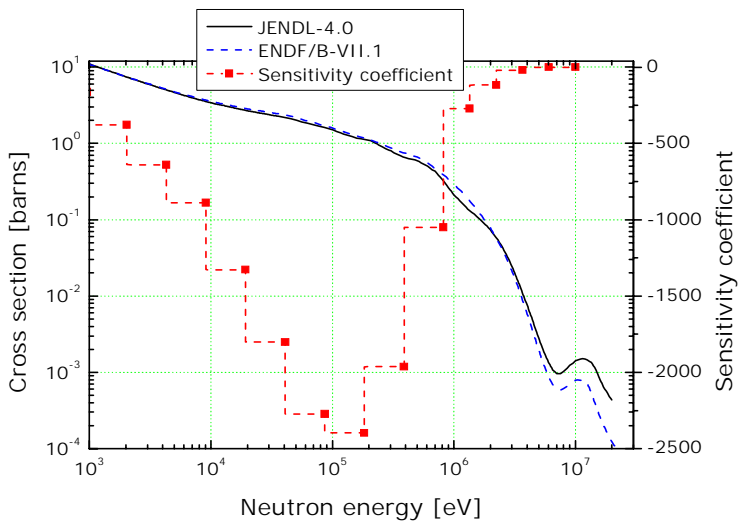

Fig. 11. Am-241 neutron capture cross section in JENDL-4.0 and ENDF/B-VII.1 libraries. Sensitivity coefficient of Am-241 neutron capture reaction for burn-up reactivity [15] is also presented.

\section{CONCLUSION}

To confirm the calculation accuracy in the neutronic design of the ADS, this study aims to compare the k-effective value at $\mathrm{BoC}, \mathrm{EoC}$ and the burn-up reactivity by using different nuclear data libraries with the same geometry proposed in the IAEA benchmark problem. The verification of the new burn-up chain for the MVP-BURN code was also performed.

In the verification of the new burn-up chain, ChainJ40, it was confirmed that the change of the isomer-state branching ratio of Am-241 capture reaction, $I R$ was the most significant. By this change, the amount of Am-242m at EoC decreased and the burn-up reactivity increased.

For the comparison with the use of different nuclear data libraries, about $1.1 \%$ dk difference was observed between JENDL-4.0 and ENDF/B-VII.1 at the BoC. About $0.7 \% \mathrm{dk} / 2.7 \% \mathrm{dk}$ differences were obtained between JENDL-4.0 and ENDF/B-VII.0/ JENDL-3.3. For the burn-up reactivity, the differences against the JENDL-4.0 result were 
$-0.065 \% \mathrm{dk} / \mathrm{kk}^{\prime},-0.706 \% \mathrm{dk} / \mathrm{kk}$ ' and $0.619 \% \mathrm{dk} / \mathrm{kk}$ ' in JENDL-3.3, ENDF/B-VII.1 and ENDF/B-VII.0 results, respectively.

For the contribution to these differences, Np-237, Am-241, Pu-239 and N-15 were the main causes in the ENDF/B-VII. 1 and VII.0 cases. In the JENDL-3.3 case, Am-241, Pu-239, Pb-206 and $\mathrm{Pb}-207$ were the main causes.

These results mean that the current nuclear data libraries are still insufficient for the neutronic design of the ADS. The enhancement of nuclear data libraries by cross section measurement is required and, moreover, integral experiments by using Np-237, $\mathrm{Am}-241, \mathrm{Pu}-239, \mathrm{~Pb}-206, \mathrm{~Pb}-207$ and $\mathrm{N}-15$ are essential.

\section{ACKNOWLEDGMENT}

The authors would like to thank Dr. Y. Nagaya of JAEA for his helpful advice and support on the MVP/MVP-BURN calculation.

\section{REFERENCES}

1. H. Oigawa, K. Tsujimoto, K. Nishihara, et al., J. Nucl. Mater., 415 (2011) 229.

2. T. Sugawara, K. Nishihara, K. Tsujimoto, et al., J. Nucl. Sci. Technol. 47(2010) 521.

3. T. Sugawara, M. Sarotto, A. Stankovskiy, et al., Ann. Nucl. Energy. 38 (2011) 1098.

4. K. Tsujimoto, T. Sasa, K. Nishihara, et al., J. Nucl. Sci. Technol. 41 (2004) 21.

5. A. Stanculescu, The IAEA Coordinated Research Project (CRP) on Analytical and experimental benchmark analyses of accelerator driven systems, OECD/NEA 11th Information Exchange Meeting, San Francisco (2010) 31.

6. K. Nishihara, T. Sugawara, H. Iwamoto, et al.,
Investigation of Nuclear Data Accuracy for the Accelerator-Driven System with Minor Actinide Fuel, OECD/NEA 11th Information Exchange Meeting, San Francisco (2010) 315.

7. M.B. Chadwick, et al., ENDF/B-VII.1 Nuclear Data for Science and Technology: Cross Sections, Covariances, Fission Product Yields and Decay Data, Nuclear Data Sheets. 112 (2011) 2887.

8. K. Shibata, O. Iwamoto, T. Nakagawa, et al., J. Nucl. Sci. Technol. 48 (2011) 1.

9. K. Shibata, T. Kawano, T. Nakagawa, et al., J. Nucl. Sci. Technol. 39 (2002) 1125.

10. M.B. Chadwick, et al., ENDF/B-VII.0: Next Generation Evaluated Nuclear Data Library for Nuclear Science and Technology, Nuclear Data Sheets. 107 (2006) 2931.

11. K. Okumura, S. Asai, Y. Hanzawa, et al., Prog. in Nucl. Sci. and Technol. 2 (2011) 369.

12. Y. Nagaya, K. Okumura, T. Mori, et al., MVP/GMVP 2; General purpose Monte Carlo codes for neutron and photon transport calculations based on continuous energy and multigroup methods, JAERI 1348, (2005).

13. K. Okumura, T. Mori, M. Nakagawa, et al., J. Nucl. Sci. Technol. 37 (2000) 128.

14. Y. Nagaya, Private communication, (2012).

15. T. Sugawara, T. Sasa and H. Oigawa, Improvement Effect of Neutronics Design Accuracy by Conducting MA-loaded Criticality Experiments in J-PARC, Proceedings of the International Conference on the Physics of Reactors (PHYSOR) (2008) 296.

16. M. Ishikawa, Application of covariances to fast reactor core analysis, Nuclear Data Sheets, 109 (2008) 2778. 